\title{
A economia clássica contra os fatos ou Sismondi entre os ricardianos ${ }^{1}$
}

\author{
Rogério Arthmar ${ }^{2}$
}

\begin{abstract}
Resumo
$\mathrm{O}$ artigo trata do debate ocorrido entre Sismondi e os economistas ricardianos, na primeira metade do século dezenove, a respeito do equilíbrio dos mercados, do papel da competição e dos efeitos da maquinaria nas sociedades industriais. A seção inicial reconstitui os principais termos do discurso crítico de Sismondi direcionado à ortodoxia clássica. A seguir, detalham-se as respostas elaboradas por McCulloch e Torrens em defesa da livre concorrência, do caráter ilimitado da demanda e do avanço da mecanização na atividade produtiva. A terceira seção considera a argumentação posterior de Sismondi na qual ele reitera sua teoria das crises de superprodução a partir de uma abordagem histórica do capitalismo. Ao final, procede-se a uma breve avaliação da herança ricardiana à economia política em vista da controvérsia examinada.
\end{abstract}

Palavras chave: Sismondi, J. C. L. Simonde de (Jean Charles Leonard), 1773-1842; McCulloch, J. R. (John Ramsay), 1789-1864; Torrens, Robert; Superprodução; Concorrência; Maquinaria.

\section{Abstract \\ The classical economics against the facts or Sismondi among the Ricardians}

This paper deals with the debate which opposed Sismondi and the Ricardian economists, in the first half of the nineteenth century, on the equilibrium of markets, the role of competition and the effects of machinery in industrial societies. At the initial section, the main content of Sismondi's critical rhetoric toward the classical orthodoxy is reconstituted. After that, the replies of McCulloch and Colonel Torrens are detailed, specially their defense of free competition and the unlimited character of demand, as well as of the inroads of machinery in the productive process. The third part considers Sismondi's rejoinder when he reinforces his theory of a general glut from a historical perspective of capitalism. In the end, and having in sight this particular controversy, a brief assessment of Ricardo's legacy to political economy is made.

Key words: Sismondi, J. C. L. Simonde de (Jean Charles Leonard), 1773-1842; McCulloch, J. R. (John Ramsay), 1789-1864; Torrens, Robert; General glut; Competition; Machinery.

JEL B12, B14, B15.

\section{Introdução}

Inconformado com a anarquia que julgava prevalecer no discurso econômico da metade do século dezenove, Thomas de Quincey ([1844] 1859, p. 6)

(1) Trabalho recebido em outubro de 2007 e aprovado em maio 2008.

(2) Professor do Programa de Mestrado em Economia da Universidade Federal do Espírito Santo (UFES), Vitória, ES, Brasil. E-mail: arthmar.vix@terra.com.br. Agradecem-se as valiosas sugestões dos pareceristas desta revista. Os erros presentes no artigo são de inteira responsabilidade do autor. 
afirmou então que não fosse pela solidez dos postulados da revolucionaria teoria de David Ricardo, todo o edifício da ciência assemelhar-se-ia a uma fabulosa miragem dos desertos árabes, pronta a desfazer-se em poeira ao mais leve sopro de controvérsia. Curiosamente, ainda que por razões opostas, outro economista britânico já havia registrado alguns anos antes a existência de situação análoga. Motivado pelo que entendia ser o império da confusão, da ambigüidade e do obscurantismo nas obras dos especialistas da época, Samuel Bailey (1825, p. vixxv) investira contra essa mesma visão ricardiana acusando-a de desfigurar a ciência e de sepultar o pensamento criativo, fazendo-se imprescindível a retirada do entulho existente para o reerguimento de toda a estrutura do saber econômico. Numa avaliação retrospectiva, pode-se dizer sem maiores riscos que nenhum dos dois autores revelou-se correto em seus diagnósticos radicalmente contrários sobre o assunto. Em primeiro lugar, porque à parte a inclinação pessoal a descartar liminarmente os eventos anômalos à sua construção teórica, o próprio Ricardo conhecia as dificuldades envolvidas nas deduções a que chegara no tocante à distribuição, bastando lembrar sua busca infrutífera por uma medida invariável do valor sem a qual os efeitos das variações salariais sobre os preços relativos restariam indeterminados (Stigler, 1962; St. Clair, 1965, cap. 3). Por outro lado, embora abalado pela crítica impiedosa de nomes como Bailey e até mesmo abandonado por seus mais notórios discípulos James Mill e McCulloch em sua tese de oposição entre salários e lucros, o sistema de Ricardo logrou granjear por décadas senão fidelidade estrita, ao menos o respeito obsequioso de gerações de economistas, incluindo-se nesse rol Stuart Mill, Cairnes, Fawcett e Marshall (Cannan, [1898] 1953, cap. VII, VIII; Blaug, 1958, cap. 3, 9-10).

Daí que a dimensão efetiva da herança de Ricardo constitua-se matéria de perene disputa na literatura econômica. De acordo com a conhecida interpretação de Marx ([1863] 1985, cap. XX), a dissolução da escola ricardiana haveria começado logo na década de 1830 em vista do empenho dos economistas vulgares em ocultar as contradições internas da teoria, bem como da mesma com a realidade capitalista, opondo-se assim ao avanço dos escritos socialistas à época. Por sua vez, Keynes ([1936] 1964, p. 32-34), creditou a força da tradição clássica dominante no entreguerras ao sucesso de Ricardo em brandir a Lei de Say contra os hereges preocupados em trazer ao centro da discussão os problemas relacionados à demanda efetiva. Já Schumpeter ([1954] 1963, p. 473-479, 598603), para quem o progresso do pensamento econômico estaria ligado à idéia de equilíbrio geral, entendia que os pioneiros do conceito de utilidade como base do valor, cujos trabalhos apareceram na primeira metade do século dezenove, 
evidenciariam a natureza efêmera da influência de Ricardo, especialmente em face do estreito número de discípulos por ele angariados. ${ }^{3}$

O presente artigo, contudo, não pretende se aprofundar de forma incisiva nesse terreno, senão que indiretamente, por meio do resgate de um dos episódios contenciosos, de resto pouco aludido, verificado durante a polêmica trajetória do sistema ricardiano na economia política clássica. Mais precisamente, busca-se, no que segue, trazer-se à luz a interação conflituosa entre, de um lado, a percepção crítica do capitalismo industrial adiantada pelo genebrino Simonde de Sismondi e, de outro, a firme reação dos ricardianos britânicos que se lhe opuseram. A retomada desse debate justifica-se porque embora se disponha de farto material sobre os ataques de Sismondi à ortodoxia clássica (por exemplo, Lutfalla, 1967; Sowell, 1972; Schaller, 1976; Arena, 1981; Gislain, 1996), escassos são os estudos dedicados às respostas a ele dirigidas pelos autores ricardianos, particularmente Torrens e McCulloch. ${ }^{4}$ Essa página específica da história do pensamento econômico possivelmente tenha sido negligenciada por tanto tempo em vista do extenso intercâmbio entre Malthus e Ricardo tender a dominar as análises da controvérsia relativa à possibilidade de saturação geral dos mercados (cf. Sowell, 1963; Cottrell, 1997; Maclachlan, 1999). Diferentemente de Malthus, porém, Sismondi desembarca em sua perspectiva crítica da economia clássica munido de substancial lastro histórico e, além disso, sem recorrer à pretensa funcionalidade do consumo improdutivo das classes agrárias. Antes, despido da indumentária fisiocrata que revestia a teoria malthusiana dos riscos da acumulação de capital, reduzindo-a assim a uma impopular defesa da renda fundiária facilmente destroçada pela poderosa munição de Ricardo, a proposta teórica de Sismondi

(3) É certo que qualquer avaliação do gênero depende do aspecto particular do sistema ricardiano que se julgue decisivo. Checkland (1949), por exemplo, ao privilegiar a Lei de Say como peça-chave do aparato teórico de Ricardo, visualizou a vitória inconteste da "Nova Escola" como resultado da unidade doutrinária e de ação dos ricardianos em seu confronto com uma brigada superior de críticos que, todavia, encontrava-se dispersa e sem um ponto teórico de convergência. Em contraposição, Meek (1950), focado na teoria do valor trabalho, diagnosticou o ano de 1830 como aquele em que ocorre o abandono definitivo de Ricardo pelos economistas britânicos, os quais se tornaram adeptos dos conceitos de utilidade ou de custo de produção como elementos explicativos do valor em oposição à retórica dos socialistas ricardianos que denunciavam o lucro como trabalho não pago apropriado pelos capitalistas. Blaug (1958), de sua parte, aponta a determinação da taxa de lucro pela produtividade agrícola como o cerne do sistema ricardiano, concluindo que poucos economistas clássicos deixaram de subscrever essa proposição. Para Hollander (1979), a oposição entre salários e lucros seria o componente teórico distintivo da contribuição de Ricardo, o que, entretanto, faria dos dissidentes e socialistas seus verdadeiros discípulos, ao invés daqueles reconhecidos como seus seguidores que, nesse ponto, como indicado, negaram seu preceptor inúmeras vezes.

(4) Excetuando-se Sowell (1972) e Bleaney (1976, p. 74-77), que dedicam alguns parágrafos ao tema, o debate, a rigor, recebeu apenas atenção tangencial na literatura quando da discussão sobre a autoria de um artigo crítico das propostas de reforma social de Robert Owen publicado na Edinburgh Review, em 1819, no qual constava também uma refutação das idéias de Sismondi, assunto ao qual se retornará adiante (veja-se Thweatt, 1974; O’Brien; Darnell, 1980). 
Rogério Arthmar

continha um ingrediente de originalidade que exigiria dos ricardianos argumentos distintos daqueles elaborados por seu mentor intelectual.

\section{A rebelião de Sismondi}

Iniciado na economia política por meio da adesão irrestrita à doutrina liberal de Adam Smith e movido pela anexação de Genebra à República Francesa, com a conseqüente imposição de impostos e taxas aduaneiras sobre a vida econômica da cidade, Sismondi publica De la Richesse Commerciale, no ano de 1803, um extenso manifesto contra a intervenção estatal e a favor do livre comércio. Ali, ao comentar a influência da legislação sobre os negócios privados, deixa ele claro que "[...] de todos os obstáculos que detêm o avanço da indústria entre os povos da Europa moderna, aqueles que lhe causam maior dano são nascidos da mania de quase todos os legisladores em almejar dirigir o comércio", concluindo, a seguir, que os interesses particulares, "[...] assim que se vêem livres, conduzem naturalmente ao bem-estar geral" (1803, v. II, p. 144). Logo depois, Sismondi dedica-se por vários anos à redação dos dezesseis tomos de sua monumental Histoire des Republiques Italiennes du Moyen Age (1807-1818), onde reconstrói a luta incessante das cidades-estado da península em prol da liberdade e contra a dominação estrangeira. É nessa etapa de sua vida que ele começa a duvidar do credo liberal, voltando-se a uma visão em que a instância econômica da sociedade não mais se constituiria força autônoma de progresso. Nessa nova concepção, a prosperidade material passaria a depender de sua conjugação com um governo republicano comprometido com a liberdade e a virtude cívica, requisitos para a promoção da felicidade geral. Como se lê, a certa altura, em Histoire: "Os italianos buscavam o bem de todos, não apenas dos senhores as expensas dos escravos [...] A partir do momento em que eles formaram seus próprios governos, e os formaram para o bem comum, eles prosperaram: enquanto as demais nações sofriam, eles elevaram-se em inteligência e virtude" (Sismondi, [1832] 1960, p. 25).

O processo de ruptura de Sismondi com o liberalismo anglo-saxão tomaria contornos mais definidos no verbete Political Economy, por ele redigido em 1815 para a Edinburgh Encyclopedia, onde já latejam diversos questionamentos sobre a eficiência do livre mercado. Na oportunidade, apesar das homenagens a Smith, Sismondi insinua que a livre concorrência não mais bastaria para garantir a harmonia de interesses entre os indivíduos, demonstrando cauteloso distanciamento de suas conviç̧ões pretéritas. Assim, por exemplo, no caso de certo produtor descobrir uma nova forma de economizar trabalho e vender seus artigos mais baratos, fenômeno enaltecido por Smith como a virtude suprema da concorrência, embora os consumidores fossem de fato beneficiados, contesta agora Sismondi, outros fatalmente seriam prejudicados: "As agruras daqueles 
produtores que perderam seu mercado e que, provavelmente, perderão parte considerável de seu capital ao venderem seus estoques a preço inferior e ao abandonarem sua antiga maquinaria, virão provavelmente contrabalançar os ganhos dos compradores" (Sismondi, 1815).

A obra mais conhecida de Sismondi, Nouveaux Principes d'Économie Politique (NP), teria sua primeira edição vinda a público em 1819, na seqüência da crise econômica iniciada em $1815^{5}$ Redigida como um desenvolvimento das idéias esboçadas em Political Economy, o prefácio alerta que a nova proposta teórica expressa no livro decorria de um problema insolúvel que acometia a economia política tradicional, a saber, sua manifesta incongruência com a realidade capitalista:

Depois de quinze anos que escrevi sobre a Richesse Commerciale, pouco li os livros de economia política; mas não cessei de estudar os fatos. Muitos deles pareciam-me rebelar-se contra os princípios que eu havia adotado. De um momento para o outro, porém, eles passaram a se encaixar, a explicarem-se uns aos outros pelo novo rumo que dei à minha teoria $(N P, 1819, \mathrm{v}$. I, p. iii).

Nos Nouveaux Principes, com efeito, perfilam-se incontáveis críticas à economia política clássica impossíveis de serem aqui elencadas em seu conjunto. Para os propósitos do presente artigo, no entanto, basta que se mencionem três flancos principais de ataque em relação aos quais os outros argumentos podem ser qualificados subsidiários. O primeiro, e talvez o mais importante por implicar ruptura irreversível com a doutrina estabelecida por Smith e Ricardo, diz respeito ao papel da concorrência considerada em seus desdobramentos sobre os produtores. Numa economia capitalista, como explica Sismondi, aquele que cria novas riquezas desconhece a verdadeira extensão de seus mercados, assim como o número e o comportamento de seus competidores diretos. $\mathrm{O}$ açoite da concorrência, por sua vez, é cego e constrange cada produtor a lutar por uma redução de custos mediante novos métodos ou pela adoção de modernos equipamentos. O crescimento automático da demanda, contudo, não é garantido de antemão, podendo ficar aquém da expansão na oferta por motivos como modificações nos hábitos dos consumidores, o surgimento de novos produtos ou mesmo uma insuficiência de renda.

Quando assim sucede, aduz Sismondi, a expansão do mercado individual de um precursor em determinada inovação teria lugar em detrimento de seus rivais. Esses últimos, premidos pela queda nos preços, tentariam igualmente

(5) A crise, deflagrada logo após as Guerras Napoleônicas, afetou principalmente a Inglaterra devido aos prognósticos excessivamente otimistas dos produtores nacionais quanto à demanda externa após o fim do bloqueio continental, ao que se somou a concorrência oriunda do progresso da industrialização nos países europeus, causando largo acúmulo de estoques nos armazéns e depósitos britânicos. Ao mesmo tempo, o governo empenhava-se na recondução da libra esterlina ao padrão-ouro, praticando uma política deflacionária que agravou ainda mais o desemprego existente (veja-se Hyndman, [1892] 1957, p. 17-23).

Economia e Sociedade, Campinas, v. 18, n. 2 (36), p. 261-285, ago. 2009. 
reduzir seus custos dispensando trabalhadores, economizando materiais, entre outros expedientes, de modo a reproduzir o preço de venda rebaixado. Os industriais que não lograssem sucesso imediato nesse esforço não poderiam, em muitos casos, trocar de ramo rapidamente devido à especialização adquirida e aos capitais imobilizados, enquanto os trabalhadores, de forma similar, dificilmente aprenderiam novos ofícios após haverem se dedicado por longo tempo a uma ocupação exclusiva. Para agravar o quadro, aqueles que permanecessem empregados trabalhariam com maior intensidade por um salário menor devido à competição dos operários demitidos, subjugados pela necessidade material, conformando uma paisagem lúgubre solenemente ignorada pela economia clássica:

Enfim, o próprio fabricante precisa de sua indústria para sobreviver e ele não renuncia a ela de bom grado; ele está sempre inclinado a atribuir a causas acidentais o declínio de seu comércio durante o ano anterior; e quanto menos ele ganha, menos se dispõe a se retirar dos negócios. A produção, portanto, prossegue ainda por muito tempo após ter satisfeito a demanda; e quando finalmente ela vem a cessar, não o faz senão após ter causado, a todos que a fizeram nascer, uma perda de capitais, de rendimentos e de vidas humanas que não se pode calcular sem estremecer (NP, 1819, v. I, p. 509-510).

A segunda linha de ataque de Sismondi aos autores clássicos viria a ser aquela mais contestada e, por isso, a que maior notoriedade lhe conferiu, qual seja, a tese de tendência inata à superprodução por parte das economias de mercado. Isso porque o laissez faire conduziria à concentração da atividade industrial em grandes estabelecimentos, dando origem à produção massiva de artigos homogêneos. A demanda da sociedade, por seu turno, não seria ilimitada como supunham os economistas em geral. Os trabalhadores, subjugados pelo desemprego ocasionado pela introdução constante de novas máquinas na produção, veriam seus rendimentos comprimidos ao mínimo necessário, não podendo eles jamais absorver a oferta total devido à insuficiência de seus ganhos pecuniários. A contrapartida desse movimento surgiria na forma de progressiva concentração da renda em mãos dos industriais, incapazes, todavia, de oferecer escoadouro seguro à produção em larga escala em vista de seu número reduzido, bem como da preferência das classes abastadas por artigos confeccionados sob encomenda e de qualidade singular. "A multiplicação indefinida dos poderes produtivos do trabalho", adverte Sismondi, "não pode, portanto, ter outro resultado que não o aumento do luxo ou dos prazeres dos ricos ociosos" ( $N P$, 1819 , v. I, p. 81). O prosseguimento de tal discrepância entre as respectivas composições da oferta e da demanda reverteria então numa disponibilidade excessiva de mercadorias seguida pela luta por mercados externos, dificuldades de 
venda, falências e desemprego, configurando uma crise de abarrotamento (engorgement) geral dos mercados. ${ }^{6}$

É extremamente importante observar que enquanto o efeito do aumento dos capitais é em geral concentrar os trabalhos em manufaturas muito grandes, o efeito das grandes riquezas é excluir quase totalmente os produtos dessas manufaturas imensas do consumo dos ricos [...] Assim, portanto, pela concentração das fortunas em um pequeno número de proprietários, o mercado interior se estreita sempre mais e a indústria é permanentemente empurrada a buscar saída nos mercados estrangeiros, onde as maiores reviravoltas the ameaçam (NP, 1819, v. I, p. 335336).

Por fim, o terceiro grande ponto de discórdia de Sismondi com a teoria clássica localiza-se em sua apreciação negativa do impacto da maquinaria no contexto da produção capitalista. A concorrência, ao aprofundar a divisão do trabalho e perante uma grande disponibilidade de capitais em busca de aplicação, fomentaria igualmente a adoção de novos equipamentos mais produtivos nos estabelecimentos industriais. À medida, entretanto, que a posterior oferta adicional se deparasse com uma demanda inerte, o processo de queda nos preços forçaria a redução nos lucros, acompanhada de cortes salariais e desemprego. Com isso, a moderna produção capitalista acabaria por revelar sua face mais desumana, a criação de um amplo contingente de trabalhadores pobres e deserdados, os proletarii, privados de todos os benefícios da nova civilização. Como frisa Sismondi no artigo Du sort des ouvriers dans les manufactures (OM): "Eles [os poderosos] devem perceber que existe na sociedade uma classe já numerosa e que tende cada dia a aumentar, para quem a presente ordem de coisas não proporciona quaisquer dos frutos da associação; eles são homens que, criando a riqueza pelo trabalho de suas mãos, jamais dela participam" ([1834] 1966, p. 198; veja-se também $N P, 1819$, v. I, p. 365-373 passim). E, em relação a esse problema crucial da sociedade de seu tempo, Sismondi denuncia a omissão crônica dos economistas clássicos, entretidos unicamente em discorrer sobre os meios de expansão da riqueza sem se preocuparem em momento algum com as condições de existência daqueles que comporiam a maior parte da sociedade civil. ${ }^{7}$ Ou, como insistiria ele anos depois no prefácio de seus Études sur l'Économie Politique (EEP): “A riqueza, a apreciação das coisas materiais, é ao mesmo tempo uma abstração, e a

(6) De uma perspectiva distinta, Sismondi vislumbra o mesmo problema ao ressaltar a dinâmica sequencial da atividade econômica em que a demanda pela produção de cada período seria limitada pelos rendimentos do período anterior. Entendida dessa maneira, a reprodução da riqueza social traria consigo a priori a possibilidade de crises de escoamento da produção. Ainda que toda a renda auferida na forma de salários e lucros tomasse a forma de procura solvente, mesmo assim poderia haver excedente de mercadorias, bastando para tanto um acréscimo líquido na aplicação produtiva do capital e, por conseguinte, na oferta total da economia ( $N P$, 1819 , v. I, cap. VI).

(7) Para uma compilação detalhada da posição dos principais economistas clássicos sobre a condição geral do povo no que concerne aos seus mais diversos aspectos como salários, saúde, educação, Poor Laws, legislação fabril e sindicatos, consulte-se Robbins (1961, p. 68-110). 
crematística (chrématistique), tendo considerado-a abstratamente e sem relação com o homem e a sociedade, erigiu seu edifício sobre uma base que se dissolve no ar" (1837, v.I, p. 4).

Uma vez desnudadas as consequências perversas sobre o bem-estar social geradas pela violenta colisão das forças competitivas, fazia-se imprescindível, para Sismondi, a reestruturação institucional das economias capitalistas contemporâneas, responsabilidade incontornável do Estado e dos legisladores:

Assim, o progresso da indústria, o progresso da produção comparado com o da população, tende a ampliar a desigualdade entre os homens. Quanto mais uma nação avança nas artes e nas manufaturas maior é a desproporção entre aqueles que trabalham e aqueles que usufruem; mais uns sofrem e mais os outros ostentam o luxo, a menos que, por meio de instituições que pareçam contrárias à finalidade puramente econômica de expansão das riquezas, o Estado corrija sua distribuição e garanta uma parte majoritária das satisfações àqueles que criam todos os meios de alcançá-las (NP, 2. ed. [1827] 1971, p. 106).

A despeito de sua enérgica condenação do capitalismo, Sismondi não nutria ideais de matiz socialista e considerava a propriedade uma "feliz usurpação", subordinada, no entanto, à sanção da sociedade conforme a utilidade pública que daí viesse a se originar. ${ }^{8}$ No caso da terra, entendia ele ser imprescindível coibir a conversão da mesma em mero veículo de enriquecimento de seus donos que, por meio de pastagens e da mecanização, buscavam ampliar seu produto líquido (a renda) às custas do produto bruto (os meios de sobrevivência dos camponeses). Para impedir essa calamidade, Sismondi sugere que a lei garantisse ao credor a expropriação dos bens de raiz quando o proprietário não honrasse suas dívidas, passando-os às mãos de indivíduos mais operosos capazes de impulsionar o cultivo e o emprego. Aliás, prossegue o genebrino, a experiência histórica ensinava que a repartição equânime da propriedade fundiária entre os descendentes assegurava um meio de vida duradouro aos pequenos cultivadores, evitando, desse modo, a miséria no meio rural, bem como a volatilidade das colheitas característica das grandes explorações agrícolas e a especulação daí decorrente (NP, 1819, v. I, p. 157-65, 252-274).

(8) Embora Sismondi insistisse em maior remuneração para os trabalhadores e na espoliação dos mesmos pelos capitalistas, suas propostas redistributivas ficavam longe de apresentar cunho radical. A seguinte passagem, extraída do artigo On the aristocratic element in free countries, ilustra bem seu pensamento sobre a questão: "Os filósofos podem sonhar com uma ordem social em que todas as distinções sejam aniquiladas, em que todos os homens sejam iguais; mas eles só podem aplicar sua teoria a uma comunidade imaginária que abjure todas as vantagens nas quais a distinção se fundamenta; uma comunidade sem memória do passado, sem elegância de costumes, sem instrução e sem riqueza; uma comunidade onde todo o trabalho para um fundo comum eliminaria as vantagens que a vida civilizada permitiu ao homem adquirir; onde todos perderiam a emulação que atualmente sustenta a coragem e onde cada qual colocaria sua indolência pessoal em oposição às necessidades da comunidade, desonerando-se de suas tarefas com repugnância sob as ordens de uma autoridade que logo se tornaria tirânica e odiada" ([1835] 1966, p. 395-396; veja-se também EEP, 1837, v. I, p. xiii-ix e, sobre a relação de Sismondi com o socialismo, Salis, 1932, p. 426-429). 
Em que pese reprovar as corporações de ofícios medievais, Sismondi, quando fala sobre as cidades, inspira-se na estabilidade das ocupações e dos ganhos dos artesãos do passado para recomendar novas políticas e instituições voltadas a atenuar a concorrência entre os trabalhadores e seus desdobramentos ruinosos. A primeira medida envolveria a supressão de todo estímulo legal, financeiro ou aduaneiro à industrialização rápida, como praticado pelos governos europeus, por ser essa forma de produção a fonte primeira das crises comerciais. Além disso, Sismondi propõe uma inovação para a época, a criação de um fundo gerenciado pelas autoridades centrais, semelhante às Poor Laws da Inglaterra, mas recolhido pelos empregadores dos ramos de atividade mais instáveis e destinado ao amparo de seus respectivos trabalhadores nos casos de desemprego, doença e acidentes. Com essa providência, as unidades industriais que não pudessem contribuir por auferir lucratividade exígua baseada em condições precárias de trabalho deveriam deixar de existir por serem, em realidade, antieconômicas. A iniciativa, justifica Sismondi, responderia a uma obrigação gritante de equidade social: "Esse ônus, que recairá somente sobre si [o industrial], será da mais inteira justiça, porque ele obtém atualmente um lucro sobre a vida dos homens, enquanto todos os danos que daí resultam ele descarrega sobre os ombros da sociedade" $(N P, 1819$, v. II, p. 362). Mais tarde, Sismondi manifestar-se-ia contra a concessão de subsídios aos produtores nas fases de derrocada dos mercados, pleiteando, em contrapartida, a execução de obras públicas como prédios municipais, vias urbanas, canais, recuperação de terras, sistemas de distribuição de água, enfim, produtos e serviços que não competissem com o setor privado e tampouco viessem a intensificar a superprodução (OM, [1834] 1966, p. 220-222; sobre a evolução do pensamento de Sismondi relativo às reformas institucionais do capitalismo, consulte-se Gislain, 1998).

Nesse momento, é interessante demarcar, ainda que brevemente, a diferença entre as concepções de Malthus e Sismondi no tocante ao papel do consumo. Desnecessário enfatizar aqui a ascendência do pensamento fisiocrata sobre a tese malthusiana de produtividade superior da exploração agrícola relativamente às demais formas de atividade econômica (Meek, 1951; Bleaney, 1976, p. 22-59). Malthus, quando admite a possibilidade de saturação geral, invoca os gastos de luxo dos senhores de terras como fator indispensável de estímulo à demanda e, portanto, de garantia de venda e de rentabilidade à produção manufatureira. Assim, escreve ele ao rebater a teoria de Ricardo sobre a acumulação:

A própria definição de terra fértil diz que é a terra que sustenta um número de pessoas maior que o necessário ao seu cultivo; e se o proprietário da terra, em vez de gastar esse excedente com bens de conforto, com artigos de luxo e com consumidores improdutivos, aplicasse esse excedente para empregar tantos trabalhadores quantos suas poupanças permitissem, é óbvio que, ao invés de 
enriquecer, ele empobreceria [...] Se [o proprietário de terras] não opta por usar esse excedente para comprar artigos de luxo ou sustentar trabalhadores improdutivos, pode jogá-lo ao mar, que o resultado é o mesmo ([1820] 1983, p. 194).

Para Sismondi, porém, a importância dos arrendatários não adviria de seu consumo improdutivo ou do número de serviçais que empregassem. No ensaio $O n$ the aristocratic element in free countries, explica ele que as aristocracias européias existentes à época distinguiam-se entre si pela linhagem familiar, pelos hábitos requintados, pela educação ou pela riqueza. Entre essas, a mais condenável seria a do segundo tipo, porquanto dedicada unicamente à elegância e ao luxo, o que Sismondi reprova de todo por considerar comportamento frívolo e arrogante. Em sua percepção, o proveito social dos proprietários de terras e das demais classes ricas adviria não de seus prazeres e confortos, mas de sua capacidade de cultivar o intelecto e fazer progredir as artes, a literatura e a ciência, em suma, a própria civilização. Além disso, o senhor de terras seria personagem importante em sua província ao servir como elemento de continuidade entre o passado e o futuro, capaz de resguardar o acesso à terra ao pobre e de promover a aplicação dos novos conhecimentos científicos à agricultura. Como dito no artigo De la richesse territoriale: "É o poder de dispor do lazer, e não do luxo, que torna a condição do rico útil à sociedade" ([1834] 1966, p. 175). ${ }^{9}$

De certa maneira, na crítica que apresenta das economias industriais, Sismondi faz convergir suas influências smithiana e republicana, já esboçadas em Histoire des Republiques Italiennes, ao lembrar que as conquistas materiais trazidas por um ambiente de liberdade e virtude não seriam perenes, podendo dissipar-se por obra da formação progressiva de uma camada de predadores incrustados no poder. Esse processo de usurpação conduziria, fatalmente, ao declínio da ordem social, assolada pela supressão da liberdade e pela deterioração dos costumes manifesta na busca incessante do interesse próprio, do luxo e dos prazeres mundanos (Romani, 2005). Assim, contrariando a interpretação comum entre os historiadores, Sismondi censura vigorosamente o domínio dos Médici em Florença, na segunda metade do século XV, por enxergar no período a expressão mais contundente do fim da era de prosperidade das cidades-estado italianas:

A casa dos Médici encorajou, em Florença, o gosto pelo prazer e pelo luxo como meio de validar seu poder; mas essa corrupção da moral começou a gerar uma reação. Todos os jovens que se entregavam com entusiasmo ao estudo das artes e

(9) Bleaney (1976, p. 42-77) afirma que a diferença entre Malthus e Sismondi residiria no fato de o primeiro defender o consumo dos proprietários de terras, enquanto o segundo favoreceria o consumo dos trabalhadores. Em princípio, embora correta, essa apreciação confere um grau indevido de proximidade entre ambos, pois os diferencia unicamente pela classe social a quem caberia restaurar o consumo deficiente. Mas Sismondi não vê no consumo um fim em si mesmo, senão que sua proposta teórica direciona-se, mais propriamente, a uma contenção do processo acumulativo de capitais e da concorrência. Para ele, os trabalhadores deveriam escolher sempre, se isso lhes fosse possível, maior tempo livre e menor riqueza, sem fazer da esfera econômica a instância prioritária de sua existência. 
das letras, que prestavam uma espécie de devoção à literatura antiga, que estudavam a filosofia grega e que foram até mesmo acusados de preferir a religião antiga dos romanos àquela da Igreja, estavam, ao mesmo tempo, profundamente ligados aos Médici. Esse sentimento eles compartilhavam com todos os libertinos, aqueles que pensavam apenas no prazer sensual e que para isso sacrificaram a liberdade do seu país; mas os que consideravam o progresso da corrupção como certo de atrair a inevitável vingança divina sobre Florença, uniram em sua compungida penitência o amor pela liberdade passada e o repúdio à tirania fundada no triunfo do vício ([1832] 1960, p. 226).

\section{A reação ricardiana: McCulloch e Torrens}

Tão pronto os Nouveaux Principes entram em circulação, o mais prolífico dos economistas clássicos, o escocês John Ramsay McCulloch, então editor da revista Scotsman, insere sem demora, no número de abril de 1819, uma áspera resenha do livro. O texto, já no início, prediz o desapontamento dos leitores que buscassem na obra de Sismondi uma extensão dos ensinamentos de Adam Smith, como seria de se antecipar em vista das lições constantes em De la Richesse Commerciale. Não obstante a concisão da resenha, McCulloch investe impiedosamente contra a proposta de regulação estatal da concorrência propugnada por Sismondi. Se o princípio da competição acarretou sofrimento às classes trabalhadoras, rebate o escocês, a única forma viável de erradicar o pauperismo seria mediante o barateamento dos artigos de consumo dos assalariados. Isso, porém, somente afigurar-se-ia viável pelo uso intensivo da maquinaria que, ao multiplicar os poderes produtivos do trabalho, reduziria o preço dos gêneros essenciais, do vestuário e da moradia, possibilitando a melhoria nas condições materiais dos trabalhadores. Dessa forma, ao habituar a população a um novo padrão de vida, as restrições morais se fariam sentir com maior peso, diminuindo o tamanho das famílias e aliviando a pressão demográfica. Não fosse isso o bastante, agrega ainda $\mathrm{McCulloch}$, as atribulações de grupos circunscritos de trabalhadores por conta da adoção de um novo equipamento seriam passageiras, enquanto os ganhos de uma riqueza profusa e acessível restariam permanentes. Inclusive, lembra ele com otimismo indisfarçado, a diminuição no preço de qualquer artigo nascido de um processo industrial mais produtivo acabaria por expandir a respectiva demanda em tal magnitude de forma a reabsorver a totalidade dos trabalhadores dispensados anteriormente. "Todo o mecanismo pelo qual o trabalho pode ser economizado e pelo qual o custo de produção se reduz deve, de fato, acrescer os confortos e prazeres de todas as categorias" $(1819$, p. 6).

Quanto à agricultura, McCulloch ressalta o papel econômico das grandes explorações em facilitar a divisão do trabalho e a introdução da maquinaria, abatendo, por conseguinte, o preço das matérias-primas e dos gêneros essenciais à população. Ao contrário do que apregoava Sismondi, as dificuldades enfrentadas pela Inglaterra seriam fruto exclusivo da interferência indevida dos governantes 
nos negócios particulares. Assim, as Poor Laws, concebidas para o auxílio aos pobres, haveriam, em verdade, debilitado o impulso à diligência e à economia por parte de seus beneficiários, além de provocar o crescimento da população. Já as restrições aduaneiras sobre as importações de cereais e outros produtos de primeira necessidade não só encareciam os mesmos, limitando o seu consumo, como também impediam um comércio mais amplo e profícuo com os parceiros comerciais do país. Por fim, a sugestão de um fundo destinado ao amparo dos trabalhadores e financiado pela contribuição dos ramos de atividade mais sensíveis às oscilações econômicas é rotulada apenas como outra perversão dos princípios de Smith, inviável em razão de o nivelamento dos lucros, como mostrado por Ricardo, impedir que um imposto ficasse restrito a uma categoria precisa de produtores. ${ }^{10}$

Em março de 1821, McCulloch publica na Edinburgh Review o artigo The opinions of Messrs Say, Sismondi and Malthus on machinery and accumulation, no qual expõe em maior minúcia os argumentos contrários às idéias de estagnação da demanda, bem como aqueles favoráveis à aplicação das artes industriais na produção. $^{11}$ Vale notar aqui que a concepção de McCulloch sobre o progresso econômico, apoiada em Smith, destacava a poupança, a divisão do trabalho, a segurança da propriedade e o livre comércio como fundamentos indispensáveis à expansão da riqueza, aos quais sobrepunha ele a proposição ricardiana relativa à fertilidade dos solos como determinante último da lucratividade geral da economia (cf. O'Brien, 1970, p. 271-313). McCulloch, contudo, revelar-se-ia o autor clássico que maior ênfase concedeu à maquinaria e às inovações como fatores de propulsão do crescimento. Tanto que, no artigo em tela, grande parte do texto revolve em torno dessa questão. Assim, pergunta ele sem delongas: se todos concordam ser desejável o aumento na destreza dos trabalhadores, como negar as vantagens associadas à maquinaria se ela nada mais faz do que acrescer a produtividade do trabalho? Caso o rendimento obtido do esforço gasto na confecção de chapéus fosse ampliado em dez vezes, o valor de cada um deles seria enormemente diminuído, favorecendo aquele segmento da humanidade que dispunha apenas de sua capacidade de trabalho para pagar pelas mercadorias. Mas o que é salutar para um produto isolado, continua McCulloch, não pode deixar de

(10) Ricardo mantinha que o imposto sobre um artigo específico seria inteiramente repassado ao preço do bem em questão, pois, de outra forma, a lucratividade do produtor cairia abaixo da taxa geral de lucro e ele ver-se-ia então compelido a abandonar sua atividade. Se o bem taxado fosse artigo de consumo dos trabalhadores, os salários aumentariam e o imposto terminaria por reduzir a taxa geral de lucro do capital (cf. Ricardo, [1817] 1996, cap. XV).

(11) O conteúdo desse artigo seria reproduzido no ensaio Machinery - cause of gluts (1824) e no capítulo referente ao assunto nas diversas edições dos seus Principles of Political Economy, evidenciando que a postura de McCulloch no tocante à possibilidade de superprodução permaneceria inalterada ao longo do tempo. Como será visto adiante, o mesmo não pode ser dito a respeito de seu julgamento sobre outros pontos críticos da industrialização. 
ser igualmente válido para o universo das mercadorias. Na hipótese de todas as linhas de produção experimentarem um salto de dez vezes na produtividade de sua mão-de-obra, os excedentes recíprocos rapidamente seriam trocados entre si, gerando maior felicidade para todos e permitindo até mesmo uma redução na jornada laboral, concedendo ao trabalhador tempo livre para o desenvolvimento da mente e outras amenidades. O incremento no salário real mediante o declínio nos preços dos bens essenciais tornaria o assalariado mais eficaz, por libertá-lo do jugo da miséria e do suor inclemente como ocorria em países de rendimento agrícola precário.

A saturação dos mercados proclamada por Sismondi e Malthus, persiste McCulloch em sua defesa da economia clássica, poderia suceder apenas de forma localizada, no caso de um ou outro produto específico e por erro de cálculo dos produtores ao anteciparem uma demanda inexistente ou limitada. A falta de um canal de saída para os estoques, nesse caso, não sobreviria por conta de produção excessiva, mas, ao contrário, por não se haver observado expansão concomitante noutros setores. Ou seja, como as necessidades são ilimitadas e os produtos trocam-se por produtos, se um deles aparenta ter sido produzido demais é porque, em verdade, outros foram produzidos de menos. Quando assim se verifica, ensina McCulloch, o remédio adequado não consiste em frear a produção, mas, sim, paradoxalmente, em fazê-la aumentar.

Parece, portanto, que a máxima facilidade de produção nunca pode ser lesiva, mas deve sempre ser acompanhada da maior vantagem. Muito de certa mercadoria pode ser ocasionalmente produzido; porém, é impossível que exista oferta exagerada de todas as mercadorias. Para cada excesso deve haver uma deficiência correspondente. A falha não está em produzir demais, mas em produzir as mercadorias que não atendem aos desejos daqueles a quem se quer vender ou, ainda, que não podem ser consumidas pelo próprio produtor. Uma vez cumpridos esses dois requisitos, o poder de produzir pode ser acrescido em mil ou em um milhão de vezes, e estaremos livres de todo excesso como se tivéssemos diminuído esse poder na mesma proporção (1821, p. 118).

De qualquer modo, McCulloch aprofunda seu raciocínio ao sustentar que com o uso de um novo equipamento indutor de oferta excessiva, como na fabricação de tecidos, por exemplo, o preço necessariamente cairia, a demanda tenderia a aumentar mais do que proporcionalmente e o emprego total do setor, ao invés de se retrair, viria a registrar expansão. Mesmo na conjectura pessimista de que a demanda não crescesse, ainda assim a queda no preço do tecido liberaria poder de compra para a aquisição de outras mercadorias, cuja rentabilidade melhoraria, atraindo os recursos livres para ampliar a produção onde fosse preciso. Ou seja, o capital e a mão-de-obra tornados redundantes pela oferta excessiva de tecidos seriam em pouco tempo absorvidos noutras áreas da economia, de sorte que a demanda efetiva total permaneceria inalterada. 
Rogério Arthmar

Já o desemprego de determinadas categorias de trabalhadores seria apenas provisório, haja vista que o treinamento obtido nas oficinas lhes permitiria, na opinião de McCulloch, transitar facilmente entre atividades congêneres. Ainda que alguns industriais se deparassem com obstáculos na recuperação do capital fixo, seu capital circulante ficaria preservado, mantendo intacto o poder de empregar trabalhadores quando de sua migração para os ramos de atividade mais lucrativos. Por fim, mas não menos importante, era preciso considerar que as máquinas não seriam dádiva da Providência, exigindo, de fato, trabalho em sua produção, representando importante fonte acessória de demanda por mão-de-obra. Embora tal argumentação se apoiasse em premissas pouco críveis, como a elevada elasticidade preço da demanda e a imunidade a perdas do capital circulante, isso não demove McCulloch de desabonar as apreensões de Sismondi e Malthus e declarar corajosamente: "Parece, portanto, embora isso esteja em desacordo com as opiniões comuns sobre o tema, que um avanço na maquinaria é sempre mais vantajoso para o trabalhador do que para o capitalista" (1821, p. 116).

No fim das contas, arremata McCulloch, o salário jamais poderia cair abaixo do patamar que garantisse a sobrevivência dos trabalhadores, embora ele pudesse sempre vir a situar-se acima desse platô. Ao longo do tempo, ora o trabalhador obteria proporção maior da renda social, ora menor. Quando ele recebesse mais, sua condição e, por extensão, a da maioria da sociedade, tornar-seia mais próspera; quando ele ganhasse menos, teria o consolo de saber que os valores perdidos haveriam se convertido em capital, ao invés de serem desperdiçados improdutivamente. Em qualquer dos casos, a situação mais desejável seria aquela em que a acumulação prosseguisse sempre a passo acelerado, com uso intensivo da maquinaria e a menor interferência possível do governo. Não existiria razão, por conseguinte, para temor algum relacionado a eventuais lapsos na capacidade de consumo da sociedade. "Sempre onde houver o poder, a vontade de consumir nunca faltará. A dificuldade real não reside em comer um bom jantar, mas em conseguir um bom jantar para comer" (1821, p. 122, itálicos no original).

A fim de se melhor compreender a reação às idéias de Sismondi na Inglaterra, é preciso fazer breve menção ao pensamento de Robert Owen, porquanto ambos os autores converter-se-iam em alvo de um duro ataque por parte do coronel da marinha britânica Robert Torrens. Isso porque, em 1819, o Duque de Kent constituía um Comitê de Sua Majestade, do qual Ricardo também faria parte, a fim de examinar os planos de Owen voltados à melhoria da condição dos pobres do país. Pouco antes, em um relatório enviado ao comitê parlamentar das Poor Laws, Owen apontara o conflito entre o interesse privado e o bem-estar coletivo, materializado na mecanização intensiva da economia, como causa maior do desemprego e da miséria dos trabalhadores. Sua proposta para redimir o 
problema compreendia a instalação de pequenas comunidades, em áreas de mil a mil e quinhentos acres e com alguns milhares de indivíduos, residindo todos em um grande prédio na forma de paralelogramo contendo restaurantes, escolas e ateliês de uso comum. Os participantes do experimento não mais se submeteriam aos rigores da divisão do trabalho, passando a dispor de um conhecimento geral que lhes permitiria transitar facilmente dos afazeres agrícolas para as lides comerciais ou manufatureiras. ${ }^{12}$

A proposta foi objeto de uma bateria de críticas no Parlamento e na imprensa, uma delas redigida por Torrens sob o título Mr. Owen's plan for relieving the national distress (1819). ${ }^{13}$ Partindo de uma posição teórica estritamente ricardiana, o militar alinha com rigor marcial os três fatores explicativos da taxa de lucro, quais sejam: (i) a qualidade dos solos em cultivo; (ii) a capacidade produtiva da mão-de-obra agrícola e manufatureira, e (iii) o salário real dos trabalhadores. Como elementos complementares, Torrens menciona ainda o livre comércio e o peso relativo da tributação. Em tais condições, a crise do pósguerra enfrentada pela Inglaterra, segundo ele, seria decorrente da expansão da agricultura a terras menos férteis, das restrições impostas ao comércio exterior e, por fim, da carga exorbitante dos impostos incidentes sobre a produção. ${ }^{14}$

A despeito das generosas intenções de Owen e de outros críticos do capitalismo, suas propostas de reforma social, observa Torrens com ironia, seriam comparáveis aos meteoros que se precipitam na Terra, projetando um brilho

(12) Ulteriormente, em seu Report to the County of Lanarck (1821), Owen detalharia o esquema que tinha em mente nos seguintes temos: "Como é de importância essencial que exista abundância de espaço no interior dos alojamentos privados, o paralelogramo, em todos os casos, esteja a associação próxima do seu número máximo ou mínimo, deve possuir largas dimensões [...] Apartamentos confortáveis com vista para os jardins e o campo e salas de tamanho adequado, frontais ao gramado interior, proporcionarão toda a comodidade, a exemplo dos demais espaços públicos, que seja útil e desejada pelos cultivadores associados [...] A agricultura, ao invés de ser, como tem sido até o presente, ocupação exclusiva do camponês e do fazendeiro, com mentalidades tão pobres quanto o solo que manejam, tornar-se-á o emprego atrativo de uma raça de homens treinados nos melhores hábitos e disposições, conhecedora das práticas mais úteis nas artes e nas ciências". O projeto, tal como visualizado por Owen, jamais saiu do papel.

(13) $\mathrm{O}$ artigo foi publicado anonimamente, daí o motivo para a discussão indicada na nota 2. Assume-se aqui a autoria de Torrens, inclusive em razão dos tediosos exemplos numéricos presentes no texto e característicos desse autor. O'Brien e Darnell (1980), além de outros argumentos convincentes, conduzem refinado teste estatístico em sua defesa da autoria de Torrens. Já Thweatt, (1974) atribui o artigo a um plágio de Torrens realizado por McCulloch, mas nunca reconhecido por esse último.

(14) Ricardo, discursando no Parlamento em de 16 de dezembro de 1919, declarou-se em guerra contra os projetos visionários de Owen, concedendo, no entanto, que o cultivo da terra com enxadas ao invés de arados, como proposto por seu compatriota, talvez pudesse gerar maior demanda por mão-de-obra, assunto a ser mais bem analisado de forma isolada. A situação de dificuldade do país, todavia, não seria resultante do uso da maquinaria, mas, sim, dos obstáculos ao comércio que reduziam a rentabilidade dos investimentos na Inglaterra, estimulando as exportações de capitais. Quando a Comissão mencionada foi instituída, em 26 de junho do mesmo ano, Ricardo congratulou Owen por seu espírito benevolente, ressaltando, porém, não acreditar numa melhoria na condição dos trabalhadores abrigados nos paralelogramos (Ricardo, [1819] 1961, v. V, p. 19-22, 303).

Economia e Sociedade, Campinas, v. 18, n. 2 (36), p. 261-285, ago. 2009. 
fulgurante sobre o caos e a desordem que deixam atrás de si. Assim, os paralelogramos estariam condenados ao insucesso desde a sua concepção, uma vez que a mera disposição dos indivíduos em forma geométrica não teria qualquer poder de afetar o rendimento do solo, as restrições comerciais com o exterior ou de manter afastado o coletor de impostos, enquanto a multiplicidade de ocupações dos residentes restringiria a divisão do trabalho e os ganhos de comércio dela oriundos. Conjuntamente, adverte ainda Torrens, a liberalidade prevista no emprego e na remuneração dos trabalhadores comprometeria o produto líquido do empreendimento, colocando a perder sua viabilidade econômica:

Devemos novamente informar esse entusiasmado e péssimo calculador que, no tocante aos direitos do cobrador de impostos, à renda da terra a ser ocupada, aos juros do dinheiro tomado por empréstimo e aos meios de acumular capital para empregar uma população crescente, o produto líquido, ou o retorno a maior sobre os adiantamentos, é o único fundo ao qual ele deve atentar ([1819] 1984, p. 83, itálicos no original).

Seja como for, o ensaio em tela inclui-se aqui em razão das considerações dirigidas à tese de Sismondi, compartilhada por Owen, de que a produção mecanizada acarretaria oferta excessiva e desemprego. No entender do coronel, a bancarrota somente não haveria se instalado ainda na Inglaterra, esmagada pelo protecionismo e pela tributação colossal, em virtude dos ganhos materiais, tanto na indústria quanto na agricultura, propiciados pela aplicação indiscriminada da maquinaria e da ciência à produção. "Isso [as pretensas perdas suscitadas pela mecanização] equivale a dizer que riqueza é pobreza e que os gêneros de primeira necessidade são impossíveis de se obter por existirem em excesso [...] A máquina a vapor, cumpre salientar, tem lutado nossas batalhas e pago os juros de nossa dívida" ([1819] 1984, p. 96).

Dado então, escreve Torrens, que a demanda e a oferta seriam vocábulos perfeitamente conversíveis entre si pelo fato de o comércio resumir-se ao intercâmbio de mercadorias, se a produção de açúcar, uvas e tabaco de um cultivador hipotético fosse trocada usualmente pelas fitas, rendas e cambraias de um mestre-manufatureiro, tal processo reproduzir-se-ia normalmente caso o número de produtores viesse a ser multiplicado mil vezes, pois cada qual prosseguiria cedendo o que lhe fosse supérfluo em troca dos artigos equivalentes de seu vizinho. A saturação teria lugar apenas para uma quantidade restrita de mercadorias, quando aquelas que lhe serviriam de contrapartida não houvessem experimentado expansão simultânea. Tais "embaraços", porém, seriam de natureza evanescente, porquanto após os ajustamentos devidos, a oferta terminaria por redistribuir-se de forma adequada e, com isso, a demanda total se reabilitaria. Como haviam demonstrado Say e James Mill, lembra Torrens, todas as pessoas, excetuando-se os raros avarentos propensos a entesourar, estariam desejosas de 
comprar qualquer artigo que estivesse à venda, quer para aplicação produtiva, quer para sua própria satisfação. Ou, cedendo a palavra ao coronel:

A demanda efetiva nada mais é do que a oferta de uma mercadoria em troca de outra. Produção aumentada, portanto, assegurado ser ela geral e bem proporcionada, é precisamente a mesma coisa que demanda. Enquanto a paixão pelo gasto ou pela acumulação de riqueza habitar o coração do homem, será impossível que o uso da maquinaria e a aplicação do poder científico ampliem a oferta de mercadorias além daquilo que a regulação da sociedade permite ser consumido ([1819] 1984, p. 100).

\section{Sismondi contra-ataca}

A investida de Torrens não haveria de esperar muito pela tréplica de Sismondi. No ano seguinte, em 1820, o genebrino faz publicar na Révue Encyclopedique o artigo Le pouvoir de consommer s'accroit-il toujours dans la societé avec le pouvoir de produire? ${ }^{15}$ Já na introdução, Sismondi identifica o autor do texto contra Owen como um obstinado discípulo da seita de Ricardo. A seguir, afirma que o argumento repetitivo de inexistência de limites à troca careceria de embasamento por omitir etapas cruciais da operação dos mercados. As necessidades e a capacidade de compra determinariam o montante da demanda e tais variáveis, insiste Sismondi, não guardariam qualquer atrelamento com os custos de produção. A mera hipótese de existência de demandas recíprocas, além disso, não poderia servir de garantia à venda final das mercadorias. $\mathrm{Na}$ feira de livros de Leipzig, por exemplo, cada livreiro dos mais distantes pontos da Alemanha chegava com numerosos exemplares de alguns poucos livros. Todos os presentes, então, passavam a trocar entre si os volumes que dispunham a fim de obter melhor sortimento das obras publicadas. Isso, entretanto, assinala Sismondi, não impedia que os piores livros ficassem dormentes nas prateleiras, pois a saída efetiva dos mesmos dependia não apenas da disposição do consumidor em adquirilo, mas, também, de sua capacidade de gasto.

Arrazoar sobre economias abstratas formadas por produtores independentes, como era hábito dos seguidores de Ricardo, contesta novamente Sismondi, em nada contribuía para elucidar o problema central da sociedade

(15) Sowell (1972) aponta esse artigo e uma passagem dos Principles de Malthus como tendo sido escritos em resposta à resenha de McCulloch, mas, em realidade, o objetivo de ambos os autores era rebater o ensaio de Torrens examinado na seção anterior. O trecho pertinente de Malthus versa sobre o intercâmbio de produtos supérfluos entre arrendatários e manufatores, onde consta: "Mas nessa troca de amabilidades, são tomadas como ponto pacífico duas coisas que são exatamente os pontos controversos. É considerado ponto pacífico o fato de sempre se preferir os artigos de luxo à indolência, e os lucros de ambas as partes serem consumidos como rendimento. Qual seria o efeito do desejo de poupar nessas circunstâncias é a questão que se coloca" ([1820] 1982, p. 190). Sua resposta sustentava que a indolência produziria falta de procura efetiva e, conseqüentemente, desemprego, enquanto a parcimônia seria prejudicial por privar arrendatários e manufatores de sua demanda recíproca.

Economia e Sociedade, Campinas, v. 18, n. 2 (36), p. 261-285, ago. 2009. 
contemporânea, a saber, a forma mais apropriada de assegurar o equilíbrio dos mercados. Numa economia capitalista, se a produção ilimitada de riqueza viria, de fato, a encontrar escoamento fácil como admitido pela teoria tradicional dependeria, inicialmente, da medida em que cada pessoa estivesse disposta a se dedicar ao trabalho árduo a fim de obter uma provisão adicional de coisas comercializáveis. $\mathrm{O}$ aumento da oferta e a redução do preço poderiam muito bem convencer o indivíduo a optar por maior tempo livre e uma vida mais frugal, perturbando assim o funcionamento de toda a engrenagem da acumulação.

Embora não se possa saber de antemão qual será a opção de cada dos cem trabalhadores, dos cem artesãos, se eles são completamente livres, como supõe $\mathrm{M}$. Ricardo, será muito difícil afirmar qual a melhor escolha que eles devem fazer para o bem-estar da sociedade. Afinal, nem todo trabalho é uma vantagem e nem todo repouso uma perda (Sismondi, 1821, p. 125).

Mesmo que aí não se ocultasse dificuldade intransponível, a história já teria comprovado que o trabalhador jamais era convidado a participar da multiplicação da riqueza e tampouco seu salário costumava experimentar aumento. No capitalismo, o proprietário das fábricas seria o destinatário final dos lucros e, por implicação, o responsável último em absorver a produção excedente. "O eventual bem-estar que possa resultar da expansão nas satisfações frívolas do luxo não é sentido por mais de uma centésima parte da nação", replica Sismondi a Torrens, complementando ainda: "Essa centésima parte, chamada a consumir o supérfluo de toda a classe trabalhadora, poderá ela ser suficiente, se o progresso das máquinas e dos capitais faz esse produto crescer sem cessar?” (1821, p. 134).

Ademais, tema esse recorrente na obra de Sismondi, a suposta convergência metafísica entre oferta e demanda surgia apenas em vista da omissão de todos os encadeamentos intermediários do raciocínio, especialmente no que se refere às barreiras aos deslocamentos do capital e da mão-de-obra entre as diversas linhas de produção da economia. Diante da abundância de gêneros agrícolas nos mercados mundiais, oriundos das estepes russas, da América do Norte e dos vales egípcios, questiona Sismondi, como fazer para que os cultivadores europeus abandonassem o campo, o "patrimônio herdado de seus pais", e se dirigissem às cidades? "Antes de fazê-lo", responde ele, "o produtor esperará que o seu capital seja esgotado até o último sou, por uma concorrência lesiva, e não renunciará à agricultura até morrer de miséria" (1821, p. 139). Situação similar acometeria as manufaturas, onde os episódios de superprodução, ainda que contidos a alguns mercados particulares, acabariam por se sobrepor uns aos outros de modo a conformar um quadro de saturação geral. Diante disso, Sismondi convoca mais uma vez os fatos que, segundo ele, teimavam em desafiar as abstrações dos economistas: 
Um grito de desespero se eleva de todas as cidades manufatureiras do Velho Mundo, e todos os campos do Novo Mundo lhe respondem. Por todo o lugar o comércio é atingido por um mesmo langor e se depara com a mesma impossibilidade de venda. O sofrimento iniciou há mais de cinco anos e longe de se acalmar, ele parece aumentar com o tempo. Em todas as profissões conhecidas há abundância de braços: como o equilíbrio de que nos falam se restabelecerá se não há ocupação que os demande? (1821, p. 141-142).

Passando ao ano de 1823, Ricardo, na ocasião, realizou breve visita a Genebra, quando então se reuniu algumas vezes com Sismondi para discutir o problema dos mercados. ${ }^{16} \mathrm{Um}$ relato sucinto dos temas abordados por ambos, acrescido de outras considerações, seria publicado por Sismondi na Revue Encyclopédique, em 1824, sob o título Sur le balance des consommations avec les productions, posteriormente incluído em apêndice à segunda edição dos Nouveaux Principes. Partindo da concordância mútua sobre a existência de uma crise de vendas na agricultura e nas manufaturas européias, Sismondi atribuiu o problema à desproporção entre oferta e consumo, enquanto Ricardo considerava a situação fruto dos vícios da ordem social, dos obstáculos à circulação dos produtos e do exagerado fardo de impostos. Além disso, Ricardo teria persistido na sua convicção de ser o livre comércio a melhor garantiria de que a produção de mercadorias se faria sempre acompanhar da procura correspondente, fosse no plano internacional, fosse no interior de cada país.

Após reiterar os custos sociais dos ajustamentos exigidos do capital e do trabalho em resposta ao uso da maquinaria na produção, Sismondi lança mão de sua bagagem histórica ao apontar os dilemas do capitalismo com que se deparava. Assim, diz ele, os sistemas econômicos do passado, apesar de seus defeitos, haviam representado, em dado momento, um avanço rumo à civilização. $\mathrm{O}$ escravismo antigo, por mais repulsivo que fosse, pusera fim ao estado de guerra interminável entre os povos e ao sacrifício dos prisioneiros. Ainda, tornou possível uma atividade econômica regular e algum tipo de acumulação, anteriormente impedidos pelos constantes preparativos de guerra e as ameaças iminentes de saques. A avareza e o luxo dos senhores, porém, surgidos com o progresso do sistema, afastaram-nos da convivência com os cativos, acirrando a exploração e elevando a mortalidade dos escravos, fase em que o império entrou em declínio. Da mesma forma, o sistema feudal, em seus primórdios, procurou reforçar os laços de proteção e clientelismo entre senhores e camponeses como forma de repovoar

(16) Como descreveu Sismondi emocionado: "M. Ricardo, cuja morte recente afligiu profundamente não somente seus familiares e amigos, mas todos aqueles a quem esclareceu com suas luzes e acalentou com seus nobres sentimentos, passou alguns dias em Genebra durante o último ano de sua vida. Discutimos, em dois ou três encontros, essa questão fundamental a respeito da qual nos encontramos em lados opostos. Ele trouxe à sua argumentação a urbanidade, a boa-vontade, o amor à verdade que o distinguiam, e uma clareza que seus discípulos não mais terão acesso, acostumados que estavam aos esforços de abstração que ele lhes exigia em seu gabinete" (NP, 2. ed. [1827] 1971, p. 344). 
os campos. Com o passar dos séculos, à medida que os primeiros tornavam-se mais opulentos e sequiosos de luxo, o jugo sobre os pobres acirrou-se, arrastando a organização feudal a um extremo insuportável. Mesmo em tais condições, todavia, os trabalhadores permaneciam ligados a terra e aos seus instrumentos, enquanto a produção mantinha-se regulada pelas necessidades que deveria atender.

No capitalismo, contudo, Sismondi identifica o completo aniquilamento de qualquer elo entre oferta e consumo. A população trabalhadora já não dispõe da menor garantia de subsistência, não sabe a quem se destinará sua produção e a remuneração que lhe cabe não retribui o esforço despendido. Além disso, cada progresso nas artes industriais exacerba a dependência da maioria relativamente ao consumo ostensivo de um grupo ínfimo de homens que em nada contribuem para o nascimento da riqueza. Aqui, atenta Sismondi, a experiência da sociedade Ateniense e das repúblicas da Antiguidade não poderia ser mais esclarecedora, quando estipularam elas uma série de atividades de caráter público, artístico e intelectual que impediam os cidadãos de serem tragados pelo trabalho manual incessante e pela avareza do comércio.

[...] o cidadão de Atenas se contentava, malgrado o progresso da indústria, em vestir-se com tecidos grosseiros e alimentar-se de pão e figos secos. Mas, certamente, a ausência de luxo não destruiu sua elegância de espírito e o refinamento de seus gostos. Ao banir todas as fruições, como legislador, ele não deixou de lado sua atividade e a força de caráter como homem privado; e quando Atenas tinha necessidade de riquezas, não para ele, mas para a pátria, o solo estéril da Ática era suficiente para os exércitos dessa república que fez tremer a Ásia Menor e a Sicília; ele era suficiente para aquelas colônias que espalharam pelas costas mais distantes os princípios de uma civilização verdadeira. $O$ único luxo de Atenas consistia nos homens que a república gerava: feliz o país que possa produzir iguais! (NP, 2. ed. [1827] 1971, p. 363).

\section{Considerações finais}

Num de seus últimos dias, Sismondi viria a exclamar: "Partirei desse mundo sem haver deixado nenhuma impressão e nada será feito" (1966, p. 50). Esse, sem dúvida, constituía-se lamento amargo de alguém que dedicara a vida a denunciar as desigualdades e a reclamar participação justa dos todos nos progressos da civilização industrial. Abatido pela grave enfermidade contra a qual lutava e, por certo, relembrando a implacável oposição que suas idéias receberam alguns anos antes, ${ }^{17}$ Sismondi talvez chegasse a uma avaliação distinta de sua

(17) Quando de sua última visita à Inglaterra e à Escócia, em 1826, Sismondi registraria amargurado, em seu diário, o contato com McCulloch em Edimburgo: "Jantamos com os Horners e encontramos McCulloch, que possui algo de rude em sua aparência e modos, e que por longo tempo me mediu com os olhos, como se eu fosse um adversário que ele devesse combater. Conduzi a conversa para a economia política: ele atacou-me nos fatos que mencionei dos relatórios de Chaptal e outros. Havia algo em seu sorriso irônico que me feriu, e então o enfrentei em seu próprio terreno, apontando todos os erros factuais, certamente numerosos, sobre o aumento da 
contribuição caso houvesse se mantido a par dos desenvolvimentos ocorridos no campo da economia política. Embora alguns, mais tarde, tivessem lhe negado papel de destaque na evolução das idéias econômicas no continente europeu (Salis, 1932, p. 422-424), é também verídico que autores franceses como VilleneuveBargemont (1784-1850), precursor do socialismo cristão na França, Joseph Droz (1773-1850), defensor do primado do bem comum sobre o laissez faire, e Eugène Buret (1810-1842), crítico ferino das abstrações da economia clássica, encontraram muito de sua inspiração nas obras de Sismondi (cf. Tuan, 1927, cap. V).

Surpreendentemente, porém, seria nos trabalhos de seus mais ferozes adversários no campo da economia política, McCulloch e Torrens, que os ideais tão caros pelos quais eles se debateram contra Sismondi viriam a ser objeto de substantivas revisões. No prefácio à terceira edição dos seus Principles (1842), McCulloch confessaria que a marcha sem precedentes da indústria na Inglaterra dificultava a formulação segura de políticas públicas por tratar-se de evento inédito na história e que, diante disso, diversos problemas econômicos permaneciam insolúveis. Essa preocupação fica aparente no capítulo dedicado ao capital e ao trabalho, onde ressalta ele a inteligência superior dos operários industriais face aos camponeses por conta das conversas e discussões coletivas mantidas entre os primeiros no ambiente fabril. Mas essa vantagem nascida da aglomeração espacial dos assalariados trazia consigo também sérios problemas. $\mathrm{O}$ primeiro deles, indica o escocês, residiria no perigo às instituições ocasionado pela percepção inevitável, por parte dos trabalhadores, das imensas desigualdades sociais geradas pelo capitalismo: "Mas um operário manufatureiro pobre", reconhece McCulloch, "que compara sua situação abjeta e desesperançada, e a da sua família e classe social, com a riqueza, o luxo e os prazeres sem limites de outras porções da comunidade, estará de todo apto a concluir que existe algo radicalmente errado num sistema que produz tais resultados" ([1825] 1965, p. 134).

Além disso, o enorme crescimento da população nos centros industriais significava que qualquer rumor de corte salarial, de aumentos nos preços dos gêneros essenciais ou de desemprego representaria grave ameaça de convulsão social e conseqüente rompimento da ordem pública. Nesse novo estado de coisas, o saber antigo seria de pouca valia, restando apenas a esperança de que as fecundas conquistas materiais do passado não viessem a resultar em ruína e desgraça coletivas. Num linguajar admirável para quem outrora se mostrara incansável paladino da indústria, escreve um McCulloch atordoado: "Talvez seja

\footnotetext{
mendicância na França e o costume francês de tomar emprestado pela vida toda. Penso ter mantido constantemente a vantagem sobre ele, mas temo haver me exasperado algumas vezes e que ele guarde algum ressentimento contra mim" ([7 ago. 1826] 1966, p. 448).
} 
possível ser dito, no final, ter sido imprudente permitir que o sistema manufatureiro alcançasse tamanha ascendência como ocorreu nesse país, e que medidas deveriam ter sido adotadas bem cedo para conter e moderar esse crescimento" ([1825] 1965, p. 137).

Mas as preocupações sociais de McCulloch não se esgotavam aí. Quando conduz exame detalhado dos argumentos favoráveis e contrários às Poor Laws, não se convence mais ele de que a iniciativa fosse prejudicial ao esforço e à economia daqueles assistidos pelos fundos de amparo aos pobres. Embora censure a transferência da gestão do sistema das paróquias para uma comissão designada pelas autoridades centrais, sua avaliação final é inequívoca em prol da manutenção do instituto: "Sem ele a paz social não poderia ser preservada; e os donos de propriedade teriam, com freqüência, que defendê-la na ponta da espada contra miríades de pobres, impelidos pela necessidade e convertidos em desesperados pelo desalento" ([1825] 1965, p. 376).

No que se refere ao versátil Torrens, o repúdio pétreo à idéia de superprodução geral viria a ser completamente esquecido quando da publicação de seu livro The Colonization of South Australia (1835). Nele, o coronel, então comissário responsável pela ocupação do território, desenvolve a teoria de que um país industrializado e adepto do livre comércio, mas dependente de matériasprimas e alimentos produzidos no estrangeiro, poderia vir a enfrentar uma pletora de capitais. Isso porque, caso a acumulação interna do ramo têxtil, por exemplo, fosse célere e superior à observada nos países produtores de algodão, haveria, cedo ou tarde, superprodução de tecidos, ocasionando queda nos preços, nos rendimentos e no emprego do setor. Da mesma forma, todas as demais atividades exportadoras da economia poderiam também sofrer abalo similar e, ainda pior, simultaneamente, gerando um quadro de superprodução geral. Tal crise não poderia ser contornada pelo simples deslocamento de recursos dentro do país, fazendo-se necessária a migração de capitais e de mão-de-obra para a colonização das áreas produtoras de matérias-primas. $\mathrm{Ou}$, como descreve o próprio Torrens:

[...] o capital manufatureiro pode ampliar-se mais rapidamente que o capital estrangeiro que cultiva os materiais das manufaturas; e, assim, em todos os departamentos da indústria fornecedora de artigos para o mercado externo pode haver um comércio excessivo (over-trading) [...] ocasionando queda geral nos preços, nos lucros e nos salários, falta de emprego e sofrimento (Torrens, 1835 apud Robbins, 1958, p. 180).

É claro que as modificações nas formas de perceber o capitalismo experimentadas por McCulloch e Torrens não foram devidas exclusivamente à ofensiva de Sismondi, embora tampouco se possa aceitar que a controvérsia entre eles não tivesse deixado impressão mais duradoura em todos os envolvidos. O que o debate examinado nas páginas anteriores parece sugerir é que qualquer tentativa 
de delimitar a contribuição teórica de determinado autor por meio de um corte definitivo de suas idéias dificilmente fará justiça ao mesmo. No caso em tela, os aspectos essenciais do pensamento de Ricardo revelaram-se não somente aqueles que ele próprio ou seus discípulos julgaram conveniente privilegiar, mas também os demais que se fizeram necessários mobilizar, ou até mesmo descartar, em função das críticas formuladas ao longo do tempo por nomes como Malthus, Sismondi ou Bailey. Por isso, é compreensível que a Lei de Say, em certa conjuntura, se mostrasse a mais importante torre da cidadela a ser protegida, enquanto noutra situação a defesa da teoria do valor trabalho viesse a aglutinar homens de caráter tão diferenciado quanto McCulloch e Torrens, ou que o combate às Corn Laws tivesse adquirido relevância no início, mas não ao final, da trajetória da Nova Escola. Se, a cada episódio contencioso, a força da lógica de Ricardo mostrava-se vitoriosa, não o fazia, contudo, sem sair do embate mais enfraquecida, de sorte que quando poucos opositores restaram, pouco também remanesceu do sistema ricardiano a ser preservado. No momento em que Jevons desferiu o golpe de graça na economia clássica, coube a Marshall tão somente fazer as exéquias e louvar a memória de seu nobre antecessor. A teoria ricardiana cumprira a sua jornada.

\section{Referências bibliográficas}

ARENA, Richard. Note sur les apports de Sismondi à la théorie classique. L'Actualité Économique, n. 4, p. 565-588, Oct./Déc. 1981.

BAILEY, Samuel. A critical dissertation on the nature, measure and causes of value. London: R. Hunter, 1825.

BLAUG, M. Ricardian economics. A historical study. New Haven: Yale University Press, 1958.

BLEANEY, Michael. Underconsumption theories. A history and critical analysis. New York: International Publishers, 1976.

CANNAN, Edwin. A history of the theories of production and distribution from 1776 to 1848. Rochester: Staples, [1898] 1953.

CHECKLAND, S. G. The propagation of Ricardian economics in England. Economica, New Series, v. 16, n.1, p. 40-52, Feb. 1961.

COTTRELL, Allin. Keynes, Ricardo, Malthus and Say's Law. Charleston, History of Economics Society Meeting, Jun. 1997.

GISLAIN, Jean-Jacques. Sismondi: naissance de l'hétérodoxie. Economies et Societés, Débats, Série D, n. 2, 1996.

Sismondi and the evolution of economic institutions. In: FACCARELLO, G. (Org.). Studies in the history of French political economy. London: Routledge, 1998.

HOLLANDER, Samuel. The economics of David Ricardo. Toronto: University of Toronto Press, 1979. 
Rogério Arthmar

HYNDMAN, H. M. Commercial crisis of the nineteenth century. New York: Augustus M. Kelley, [1892] 1967.

KEYNES, John M. The general theory of employment, interest and money. London: Harcourt Brace Jovanovich, [1936] 1964.

LUTFALLA, Michel. Sismondi - critique de la loi des débouchés. Revue Économique, v. 18 , n. 4, p. 654-673, 1967.

MACLACHLAN, Fiona. The Ricardo-Malthus debate on underconsumption: a case study of economic conversation. History of Political Economy, v. 31, n. 3, p. 563-574, Fall 1999.

MALTHUS, Thomas R. Princípios de economia política e considerações sobre sua aplicação prática. São Paulo: Abril Cultural, 1983.

MARX, Karl. Teorias da mais-valia. História crítica do pensamento econômico. São Paulo: DIFEL, [1863] 1985. v. III.

McCULLOCH, John R. Review of Nouveaux principes d'économie politique. The Scotsman, Saturday $24^{\text {th }}$, p. 6, Apr. 1819.

- The opinions of Messrs Say, Sismondi e Malthus on the effects of machinery and accumulation, stated and examined. Edinburgh Review, p. 102-123, Mar. 1821.

Employment of machinery - cause of gluts. The Scotsman, Wednesday $6^{\text {th }}$, p. $1-2$, Saturday $16^{\text {th }}$, p. $1-2$, Oct. 1824.

1965.

The principles of political economy. New York: Augustus M. Kelley, [1825]

MEEK, Ronald. The decline of ricardian economics in England. Economica, New Series, v. 17, n. 65, p. 43-62, Feb. 1950.

Physiocracy and the early theories of under-consumption. Economica, New Series, v.18, n. 71, p. 229-269, Aug. 1951.

O'BRIEN, D. P. J. R. McCulloch. A study in classical economics. London: George Allen \& Unwin, 1970.

; DARNELL, A. C. Torrens, McCulloch and the "Digression on Sismondi": whose digression? History of Political Economy, v. 12, n. 13, p. 383-395, Fall 1980.

OWEN, Robert. Report to the county of Lanarck [1821]. In: KAPP, K. W.; KAAP, L. L. (Org.). History of economic thought. A book of readings. New York: Barnes \& Nobles, 1949.

QUINCEY, Thomas de. The logic of political economy. Boston: Ticknor and Fields, [1844] 1859.

RICARDO, David. Princípios de economia política e tributação. São Paulo: Nova Cultural, [1819] 1996.

Obras y correspondência. Discursos y testimonios 1819-1823. México: Fondo de Cultura, 1961. v. V. 
ROBBINS, Lionel. Robert Torrens and the evolution of classical economics. London: Macmillan, 1958.

The theory of economic policy in English classical political economy. London: Macmillan, 1961.

ROMANI, Roberto. The republican foundations of Sismondi's Nouveaux principles d'économie politique. History of European Ideas, n. 31, p. 17-33, 2005.

SALIS, Jean-R de. Sismondi 1775-1842. La vie et l'œuvre d'un cosmopolite philosophe. Paris: Librairie Ancienne Honoré Champion, 1933.

SCHALLER, François. Les jugements de Sismondi sur l'économie politique de son temps. In: MICHAUD, Sven S. (Org.). Sismondi Européen. Actes du Colloque international tenú à Genève les 14 et 15 septembre 1973. Genéve: Slatkine, 1976.

SCHUMPETER, Joseph A. History of economic analysis. London: George Allen \& Unwin, [1954] 1963.

SISMONDI, J. C. L. Simonde de. De la richesse commerciale, ou principes d'économie politique, appliqués a la legislation du commerce. Genève: J. J. Paschoud, 1803. 2v.

Acesso: mar. 2007.

Political economy, 1815. Disponível em: <http://cepa.newschool.edu/het/>.

Nouveaux principes d'économie politique ou de la richesse dans ses rapports avec la population. Paris: Delaunay, 1819. 2v.

Nouveaux principes d'économie politique ou de la richesse dans ses rapports avec la population. [Reimpressão da 2. ed., 1827] Paris: Calmann-Lévy, 1971.

A history of the Italian republics, being a view of the rise, progress and fall of Italian freedom. New York, Harper and Brothers, [1832] 1960.

Political economy and the philosophy of government. A series of essays selected from the works of M. de Sismondi. Augustus M. Kelley, New York, 1966.

1838.

Études sur l'économie politique. Paris: Treuttel et Würtz, v. I, 1837; v. II,

STIGLER, George J. The Ricardian theory of value and distribution. In: SPENGLER, J. J.; ALLEN, W. R. (Org.). Essays in economic thought: Aristotle to Marshall. Chicago: Rand McNally, 1962. p. 407-430.

SOWELL, Thomas. The general glut controversy reconsidered. Oxford Economic Papers, v. 15, n. 3, p. 193-203, Nov. 1963.

Sismondi: a neglected pioneer. History of Political Economy, v. 4, n. 1, p. 62-88, Spring 1972.

ST. CLAIR, Oswald. A key to Ricardo. New York: Augustus M. Kelley, 1965.

THWEATT, William. The digression on Sismondi: by Torrens or McCulloch? History of Political Economy, v. 6, p. 435-453, 1974.

TORRENS, Robert. The economists refuted and other early economic writings. Fairfield: Augustus M. Kelley, 1993. 
Rogério Arthmar

TUAN, Lao-Mao. Simonde de Sismondi as an economist. New York: Columbia University Press, 1927. 